\title{
Rancang Bangun Sistem Kendali Penyiram Tanaman Jalan Berbasis Kelembaban
}

\author{
Hardi Putra Atyasa', Nugroho Suharto², Azam Muzakhim Imammuddin ${ }^{3}$ \\ 1,2,3 Program Studi Jaringan Telekomunikasi Digital, \\ Jurusan Teknik Elektro, Politeknik Negeri Malang, Indonesia
}

1 putraatyasa97@gmail.com, ${ }^{2}$ nugroho.suharto@ polinema.ac.id, ${ }^{3}$ azam@ polinema.ac.id

\begin{abstract}
Due to the length of the plant area on the road, usually many plants wither or are damaged due to uncontrolled watering. Watering staff on the street usually water the plants periodically. Watering the road plants sometimes causes small congestion and there are parts of the plants that are not watered because it is done manually. The purpose of this research is to create a design of road plant watering control system moisture-based using a soil moisture sensor, nodeMCU, relay module, voltage regulator, and dynamo sprayer. The results of the performance of this device are influenced by the time of the watering schedule and the soil moisture content of the plants. The results of the design and testing of the tool obtained an automatic plant watering system design and can monitor plant soil moisture with the Thingspeak platform via a web browser. Watering will be done automatically when the time of the watering schedule is entered and the soil moisture is dry. The results of the soil sensor readings on soil moisture form an ADC value range of 500 - 900 when the sensor is wet, while 901 - 1023 when the sensor is dry. The delay value for sending data from the soil moisture monitoring system is 0.473 ms at node $1,0.433$ ms at node 2, and 0.245 at node 3. Where the delay value for each node is categorized as good (0 - 150 ms) according to ITUT standards.
\end{abstract}

Keywords - Street Plants, Sensor Soil Moisture, nodeMCU, dynamo sprayer

\begin{abstract}
Abstrak - Karena panjangnya lahan tanaman di jalan biasanya banyak tanaman yang layu atau rusak karena tidak terkontrol penyiramannya. Petugas penyiram tanaman di jalan biasanya menyiram tanaman tersebut secara berkala. Penyiraman tanaman jalan kadang menimbulkan kemacetan kecil dan ada bagian tanaman yang tidak tersiram karena dilakukan secara manual. Tujuan dari penelitian ini adalah membuat rancang bangun sistem kendali penyiram tanaman jalan berbasis kelembaban menggunakan sensor soil moisture, nodeMCU, modul relay, regulator voltage, dan dynamo sprayer. Hasil kinerja perangkat ini berpengaruh dari waktu jadwal penyiraman dan kadar kelembaban tanah pada tanaman. Hasil Perancangan dan pengujian alat diperoleh rancangan sistem penyiram tanaman secara otomatis dan dapat memonitor kelembaban tanah tanaman dengan platform thingspeak melalui web browser. Penyiraman akan dilakukan otomatis saat masuk waktu jadwal penyiraman dan kelembaban tanah kering. Hasil pembacaan sensor soil terhadap kelembaban tanah berupa range nilai ADC sebesar 500 - 900 saat kondisi sensor basah sedangkan 901 - 1023 saat sensor dalam keadaan kering. Nilai delay pengiriman data hasil sistem monitoring kelembaban tanah sebesar $0.473 \mathrm{~ms}$ pada node $1,0.433 \mathrm{~ms}$ pada node 2, dan 0.245 pada node 3. Dimana nilai delay tiap node tersebut dikategorikan baik (0 - 150 ms) sesuai standar ITUT.
\end{abstract}

Kata kunci- Tanaman Jalan, Sensor Soil Moisture, nodeMCU, dynamo sprayer

\section{PENDAHULUAN}

Tanaman jalan merupakan sektor penting bagi masyarakat. Selain untuk memperindah, tanaman juga berfungsi untuk sumber kehidupan manusia. Tanaman dijalan dapat berfungsi sebagai pelindung dari panas, penghasil oksigen dan lain - lain. Adanya tanaman jalan perumahan dapat mengurangi dampak pemanasan global [1].

Namun terdapat kendala dalam penyiraman tanaman tersebut[2]. Karena panjangnya lahan tanaman di jalan biasanya banyak tanaman yang layu atau rusak karena tidak terkontrol penyiramannya[3]. Karena faktor cuaca yang tidak menentu menyebabkan kelembaban tanah tanaman kering dan tanaman akan rusak[4-7]. Petugas penyiram tanaman jalan biasanya menyiram tanaman tersebut secara berkala. Dalam proses penyiraman terkadang juga menyebabkan kemacetan karena truk penyiram tanaman yang ukurannya besar sehingga jalan tertutupi. Penyiraman biasanya memakan waktu dan kurang efisien [8-9]. Oleh karena itu dibutuhkan sistem penyiraman otomatis dan sensor kelembapan tanah untuk memonitor keadaan tanah tanaman.

Maka dari itu pada penelitian ini akan dibahas tentang pembuatan "Rancang Bangun Sistem Kendali Penyiram Tanaman Jalan Berbasis Kelembaban“. Dalam sistem dibutuhkan 3 node sensor yang bersifat statis (tidak bergerak). Tiap node memiliki sensor soil yang dapat mengetahui kelembaban tanah didasarkan dari kadar air yang ada dalam tanah tersebut. Sensor soil dihubungkan ke mikrokontroler yaitu nodeMCU [8]. Mikrokontroler nodeMCU berfungsi sebagai otak pada tiap node [5][10] yang akan menjalankan perintah penyiraman tanaman secara otomatis pada waktu yang ditentukan dan kadar kelembapan tanaman kering. NodeMCU juga bertugas mengirimkan data kelembapan tanah ke server platform thingspeak. Data kadar kelembapan tanah nanti dapat diakses pada tampilan web melalui platform thingspeak, serta dilakukan pengujian sensor [11] dan QoS untuk mengetahui performa sistem [12-13]. 


\section{METODE}

\section{A. Blok Diagram Sistem}

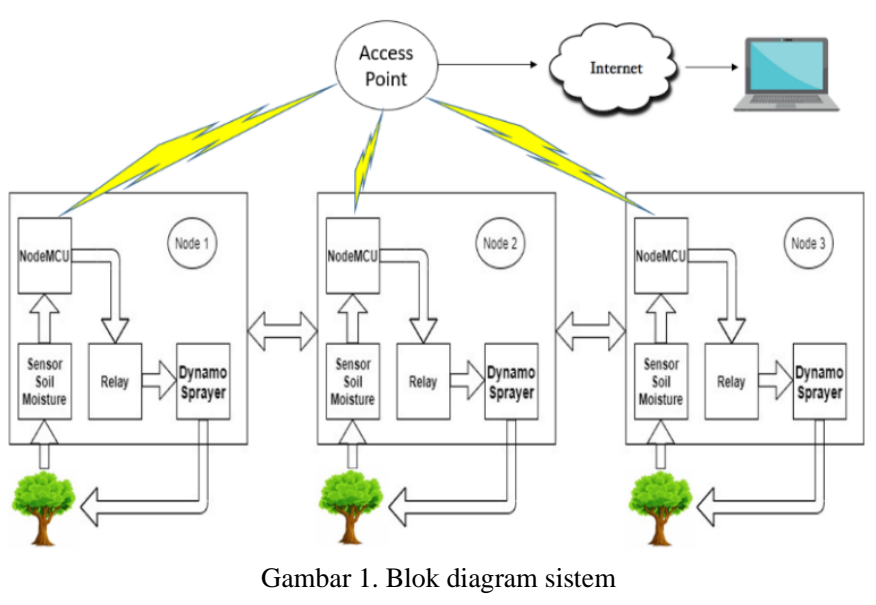

Pada Gambar 1 merupakan blok diagram keseluruhan penelitian yang akan dilakukan. Input data berasal dari sensor soil yang digunakan untuk mengetahui kadar kelembaban tanah. Langkah pertama adalah merancang node - node yang dibutuhkan untuk mengetahui kelembaban tanah pada lahan tanaman. Node yang dibutuhkan untuk sistem monitoring ada 3. Setiap node memiliki beberapa komponen yaitu sensor soil, nodeMCU, dan dinamo sprayer DC. Sensor soil terhubung ke nodeMCU untuk memproses hasil data kelembaban tanah. NodeMCU terhubung secara wireless ke access point agar bisa terhubung ke jaringan internet dan dapat ditampilkan dalam web. NodeMCU juga melakukan perintah otomatis penyiraman tanaman pada waktu yang sudah ditentukan dan jika kadar kelembaban tanah kering. Langkah kedua adalah membangun sistem seperti pada gambar 1 dan mengkonfigurasi masing - masing node agar bisa terhubung ke internet dan dapat mengupload ke server platform thingspeak.

\section{B. Algoritma Alur Kerja Sistem Keseluruhan}

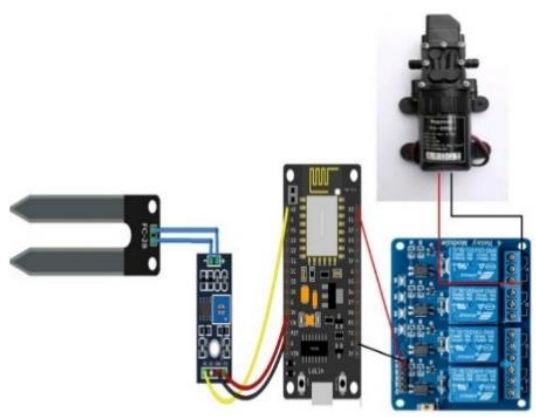

Gambar 2. Wiring diagram

Pada Gambar 2 adalah hasil wiring diagram keseluruhan rangkaian secara umum. NodeMCU sebagai mikrokontroler terhubung dengan sensor soil untuk membaca input dan memproses hasil inputan. NodeMCU terhubung dengan relay yang akan aktif dengan kondisi tertentu dan akan mengaktifkan dinamo sprayer.

\section{Algoritma Alur Kerja Sistem Keseluruhan}

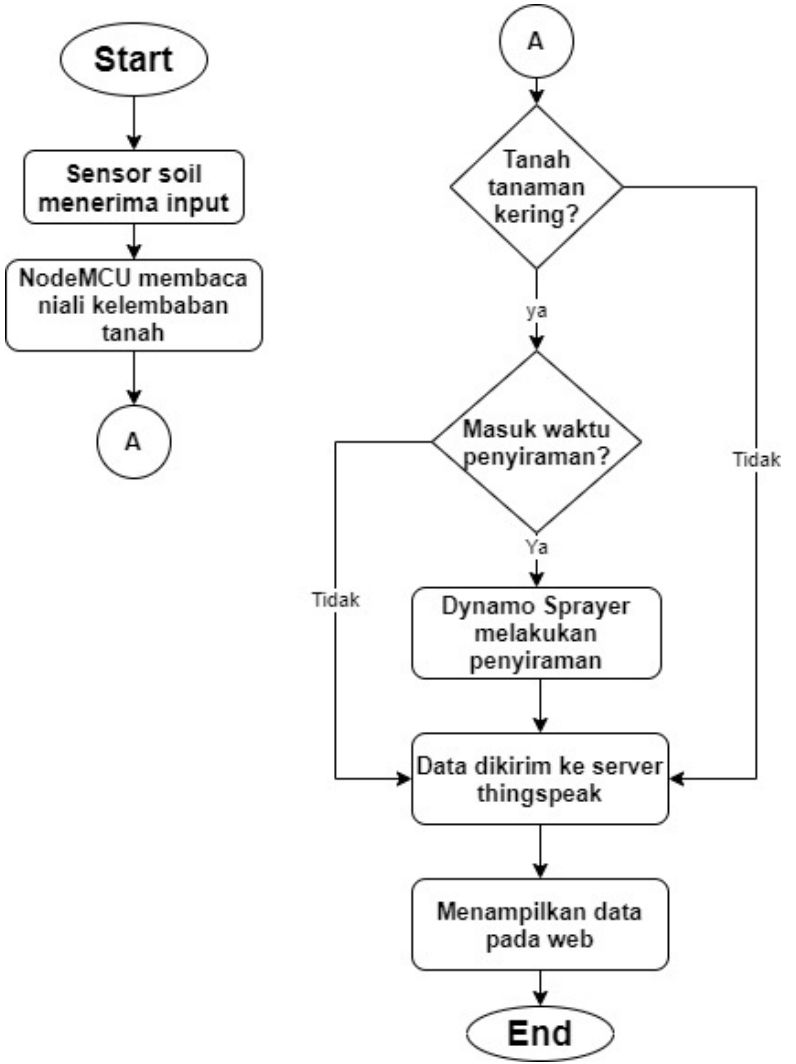

Gambar 3. Flowchart algoritma sistem keseluruhan

Gambar 3 menunjukkan flowchart keseluruhan sistem. Yang pertama yaitu meletakkan sensor soil pada tanah dekat tanaman, kemudian sensor soil akan menerima input kadar kelembaban tanah dan nilai tersebut akan dibaca oleh mikrokontroler nodeMCU. Jika sudah masuk waktu penyiraman tanaman yang telah ditentukan, maka akan dilakukan penyiraman saat status kelembaban tanah kering. Sedangkan saat status kelembaban tanah basah tidak dilakukan penyiraman. Setelah melakukan proses pembacaan nilai input, data kelembaban tanah akan diupload ke thingspeak secara realtime agar bisa ditampilkan pada web browser.

\section{HASIL DAN PEMBAHASAN}

\section{A. Hasil Perancangan Hardware}

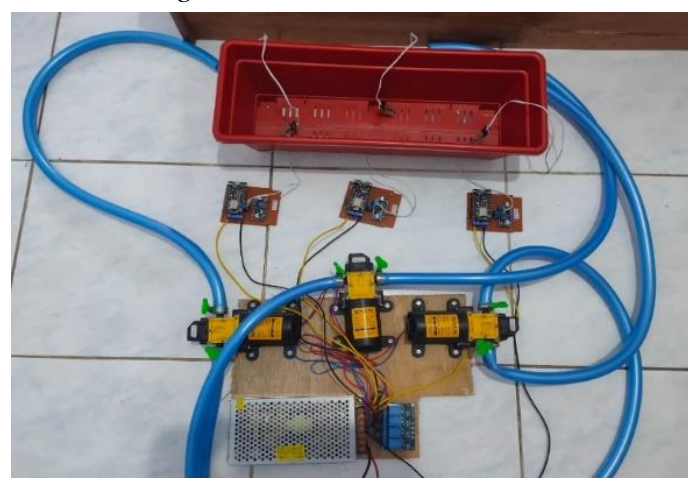

Gambar 4 Hasil implementasi rangkaian keseluruhan 
Gambar 4 menunjukkan hasil keseluruhan bagian mekanik penyiram tanaman dan juga bagian node sensor tiap node. Terdapat 3 node yaitu node 1 , node 2 , dan node 3 yang dipasang di tiga titik tanaman untuk memonitor kadar kelembaban tanah. Bagian mekanik penyiraman berfungsi melakukan penyiraman tanaman.

Bagian node berfungsi sebagai mikrokontroler dan pengirim data ke server dapat dilihat seperti gambari berikut:

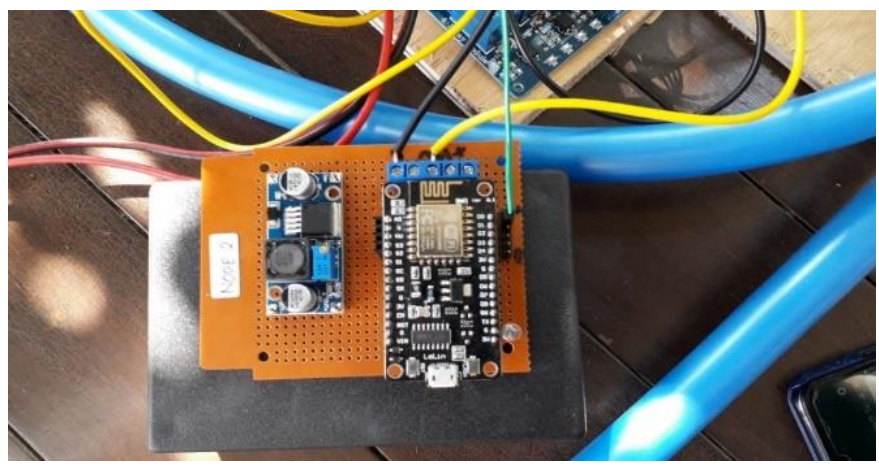

Gambar 5 Node sensor

Gambar 5 menunjukkan rangkaian mikrokontroler pada tiap node. Pada rangkaian terdapat mikrokontroler nodeMCU ESP8266 yang dihubungkan dengan sensor soil moisture, modul regulator, dan modul relay untuk menyalakan dynamo sprayer. Node yang dipasang di tiap titik dapat kita monitor kadar kelembaban tanahnya dengan mengakses platform thingspeak dengan web browser.

\section{B. Hasil Perancangan Software Monitoring}

Gambar 6 merupakan tampilan monitoring pada platform thingspeak. Setelah melakukan login ke thingspeak akan langsung ditampilkan grafik perubahan kadar kelembaban tanah dan juga persentase kelembaban tanah secara realtime. Persentase didapat dari range nilai data analog atau ADC $(0-$ 1023) yang jika kering tegangan output akan menurun sedangkan jika basah tegangan output akan naik. Didapatkan range nilai 500 - 900 (dalam ADC) adalah saat kondisi sensor basah, sedangkan nilai 901 - 1023 (dalam ADC) adalah saat sensor dalam keadaan kering.

\section{Pengujian Karakteristik Sensor}

Pengujian karakteristik sensor dilakukan untuk mengetahui apakah sensor berjalan dengan baik dan hasil yang dibaca oleh sensor sesuai dengan hasil tampilan monitoring.

Dari hasil yang didapat pada table 1 menunjukkan bahwa nilai data analog dan nilai yang ditampilkan pada tampilan monitoring sesuai.

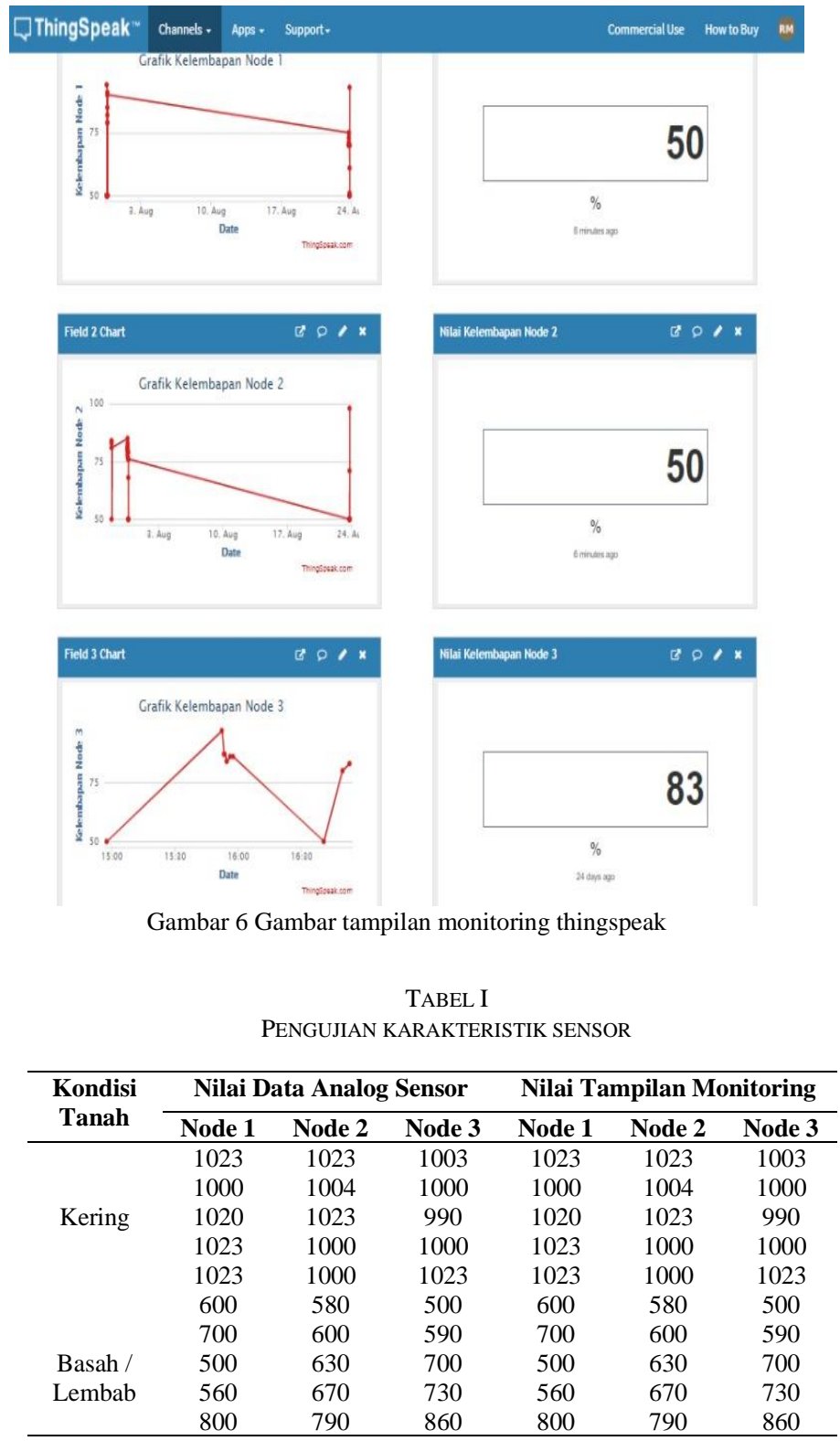

\section{Pengujian Penyiraman Berdasarkan Waktu dan}

Kelembaban Tanah

Pengujian penyiraman dilakukan untuk mengetahui keakurasian reaksi relay terhadap inputan dari sensor soil dan perintah waktu penyiraman.

TABEL II

PENGUJIAN NODE 1

\begin{tabular}{cccc}
\hline $\begin{array}{c}\text { Keterangan } \\
\text { Waktu }\end{array}$ & $\begin{array}{c}\text { Nilai Data } \\
\text { Analog } \\
\text { kelembaban }\end{array}$ & $\begin{array}{c}\text { Status } \\
\text { Kelembaban }\end{array}$ & Status Relay \\
\hline $\begin{array}{c}\text { Diluar } \\
\text { waktu yang } \\
\text { ditentukan }\end{array}$ & 1023 & Kering & $\begin{array}{c}\text { High (tidak } \\
\text { menyiram) }\end{array}$ \\
\hline & 1020 & Kering & $\begin{array}{c}\text { High (tidak } \\
\text { menyiram) }\end{array}$ \\
\hline
\end{tabular}




\begin{tabular}{cccc}
\hline $\begin{array}{c}\text { Keterangan } \\
\text { Waktu }\end{array}$ & $\begin{array}{c}\text { Nilai Data } \\
\text { Analog } \\
\text { kelembaban }\end{array}$ & $\begin{array}{c}\text { Status } \\
\text { Kelembaban }\end{array}$ & Status Relay \\
\hline 600 & Basah & $\begin{array}{c}\text { High (tidak } \\
\text { menyiram) }\end{array}$ \\
$\begin{array}{ccc}\text { High (tidak } \\
\text { menyiram) }\end{array}$ \\
Basah & Basah & $\begin{array}{c}\text { High (tidak } \\
\text { menyiram) } \\
\text { Low }\end{array}$ \\
$\begin{array}{c}\text { Dalam } \\
\text { waktu yang }\end{array}$ & 1020 & Kering & $\begin{array}{c}\text { Kenyiram) } \\
\text { Low } \\
\text { ditentukan }\end{array}$ \\
1023 & 500 & Kering & $\begin{array}{c}\text { Low } \\
\text { (menyiram) }\end{array}$ \\
& 559 & Basah & $\begin{array}{c}\text { High (tidak } \\
\text { menyiram) }\end{array}$ \\
& 800 & Basah & $\begin{array}{l}\text { High (tidak } \\
\text { menyiram) } \\
\text { High (tidak } \\
\text { menyiram) }\end{array}$ \\
\hline
\end{tabular}

Seperti yang ada pada tabel 2 pengujian node 1 , relay akan berstatus high (tidak melakukan penyiraman) jika belum memasuki waktu yang ditentukan atau kadar kelembaban tanah berkategori basah. Sedangkan saat berkategori kering dan memasuki waktu yang ditentukan relay akan berstatus low (melakukan penyiraman).

\section{E. Pengujian Delay}

Pengujian Quality of Service (QoS) bertujuan untuk mengetahui performansi sistem dengan mengukur parameter yaitu delay. Pengujian dilakukan menggunakan koneksi jaringan wifi yang terhubung pada internet. Untuk software yang digunakan adalah wireshark. Pengujian dilakukan untuk mengetahui delay yang terjadi saat pengunggahan data ke server thingspeak.

Hasil pengujian Delay didapatkan seperti berikut:

\section{[Time delta from previous captured frame: 0.000473000 seconds]}

Gambar 7. Hasil delay node 1

Dari hasil delay yang didapatkan menunjukkan delay sebesar $0.473 \mathrm{~ms}$ yang berarti lactency yang terjadi tidak buruk atau koneksi tergolong bagus.

\section{[Tine delta from previous captured frane: 0.600443000 seconds]}

Gambar 8. Hasil delay node 2

Dari hasil delay yang didapatkan menunjukkan delay sebesar $0.443 \mathrm{~ms}$ yang berarti lactency yang terjadi tidak buruk atau koneksi tergolong bagus.

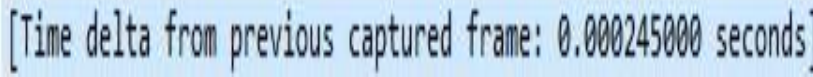

Gambar 9 Hasil delay node 3
Dari hasil delay yang didapatkan menunjukkan delay sebesar $0.245 \mathrm{~ms}$ yang berarti lactency yang terjadi tidak buruk atau koneksi tergolong bagus.

\section{KESIMPULAN}

Setelah dilakukan pengujian dan analisa terhadap sistem yang telah dibuat maka dapat disimpulkan bahwa: Penyiraman tanaman jalan secara manual dilakukan setiap hari pada jam yang dijadwalkan menggunakan truk air. Maka dari itu alat penyiraman melakukan penyiraman setiap hari pada jam tertentu dan untuk menghemat air penyiraman dilakukan jika kondisi tanah tanaman tidak membutuhkan untuk disiram. Penyiraman dilakukan secara otomatis pada saat jadwal penyiraman yang ditentukan dan juga dengan memanfaatkan pembacaan sensor soil terhadap kelembaban tanah berupa range nilai ADC. Tidak akan dilakukan penyiraman jika sensor membaca nilai ADC sebesar 500 - 900 saat kondisi sensor basah sedangkan saat terbaca nilai ADC 901 - 1023 dimana sensor dalam keadaan kering akan dilakukan penyiraman. Pentransmisian data dari tiap node ke server melalui access point terlebih dahulu dengan jarak jangkau maksimal dari node ke access point adalah 30 meter. Setelah itu access point akan meneruskan ke server thingspeak sehingga data bisa ditampilkan pada tampilan web.

\section{REFERENSI}

[1] A. F. Zulkarnain and M. R. Alfarisi, "Sistem Monitoring Tanaman Berbasis Internet of Things IBM Bluemix," ISU Teknol. STT MANDALA, vol. 14, no. 1, pp. 100-106, 2019.

[2] W. P. Putra, E. Ismantohadi, M. Qomarrudin, T. Informatika, P. Negeri, and I. Pendahuluan, "Sistem Monitoring Tanaman Hortikultura Pertanian," $J$. Teknol. dan Inf. UNIKOM, vol. 9, no. 1, pp. 45-54, 2019.

[3] E. Z. Kafia, E. K. Allo, and D. J. Mamahit, "Rancang Bangun Penyiram Tanaman Berbasis Arduino Uno Menggunakan Sensor Kelembaban YL-39 Dan YL69," J. Tek. Elektro dan Komput., vol. 7, no. 3, 2018.

[4] G. sari merliana, "Rancang Bangun Alat Penyiram Tanaman Otomatis Menggunakan Sensor Kelembaban Tanah," J. Electr. Technol., vol. 3, no. 1, pp. 13-17, 2018.

[5] D. Permatasari, M. Kusumawardani, and N. Suharto, "PENERAPAN AODV ( AD HOC ON DEMAND DISTANCE VECTOR ) ROUTING PROTOCOL DI ARDUINO UNO SEBAGAI TRANSFER DATA PADA LAHAN PERKEBUNAN," J. JARTEL, vol. 9 , pp. 525-531, 2019.

[6] N. Dwi, "Evaluasi Pemilihan Jenis dan Penataan Tanaman Median Jalan Kota Malang," J. Produksi Tanam., vol. 3, no. 4, pp. 269-277, 2015.

Rasudin, "Quality of Services (Qos) Pada Jaringan Internet Dengan Metode Hierarchy Token Bucket," J. Penelit. Tek. Inform. Univ. Malikussaleh, vol. 4, no. 1, pp. 210-223, 2014. 
[8] R. P. Nur Laili, F. A. S. A. Soelistianto, N. Zakaria, and N. Hidayati, "Monitoring Kekenyalan Tahu Kedelai dengan Sensor Kapasitif Menggunakan Mikrokontroller Berbasis Android," E-JOINT (Electronica Electr. J. Innov. Technol., vol. 2, no. 1, pp. 35-42, 2021, doi: 10.35970/e-joint.v2i1.752.

[9] U. P. Sari, "Platform Thingspeak," Univ. Sriwij., 2016, [Online]. Available: http://edocs.ilkom.unsri.ac.id/474/1/09011181320003 _Ulan Purnama Sari_TASK2.pdf.

[10] Binus, "QoS (Quality of Services)." https://onlinelearning.binus.ac.id/computerscience/post/qos-quality-of-services.

[11] Y. Imanniarti, "Design of Post Operation Recovery Room Control System Based on Wireless Sensor Network", Jaringan Telekomunikasi, vol. 8, no. 1, pp. 32-40, Mar. 2019.

[12] N. Hidayati and Suwadi, "Analisis Kinerja TCP/IP untuk Jaringan Nirkabel Bergerak 3G di Surabaya," J. Tek. ITS, vol. 5, no. 2, pp. A941-A945, 2016.

[13] D. Priadi, "Measurement of Quality of Service (QoS) in File Sharing Applications with the Android-Based Client Server Method", Jaringan Telekomunikasi, vol. 6, no. 1, pp. 39-49, May 2018. 